\title{
Effect of the austenitizing temperature on the kinetics of ferritic grain growth under continuous cooling of a $\mathrm{Nb}$ microalloyed steel
}

\author{
A.B. Cota ${ }^{a, *}$, C.A.M. Lacerda ${ }^{b}$, F.L.G. Oliveira ${ }^{b}$ \\ F.A. Machado ${ }^{b}$, F.G. da Silva Araújo ${ }^{\text {a }}$ \\ a Department of Physics/REDEMAT, Federal University of Ouro Preto, Praça Tiradentes 20, Centro 35400000 Ouro Preto, Brazil \\ ${ }^{\mathrm{b}}$ REDEMAT, Federal University of Ouro Preto, Praça Tiradentes 20, Centro 35400000 Ouro Preto, Brazil
}

Received 3 September 2003; received in revised form 21 May 2004; accepted 25 May 2004

Available online 3 July 2004

\begin{abstract}
The continuous cooling kinetics of the nucleation and growth of the ferritic phase was studied on a Nb microalloyed steel. Johnson-Mehl-Avrami equations were found for three austenitizing conditions and a direct relation between the time exponent and the transformation time was revealed.
\end{abstract}

(C) 2004 Published by Elsevier Ltd. on behalf of Acta Materialia Inc.

Keywords: Austenitizing; Nb microalloyed steels; Ferritic grain growth kinetics

\section{Introduction}

The austenite/ferrite transformation has been studied by many authors [1-4], as a function of the cooling rate, of the previous austenite grain size and of the degree of deformation on the non-recrystallization region.

The effect of the austenitizing temperature on the austenite transformation kinetics, for a $\mathrm{Nb}$ microalloyed steel, was studied by differential thermal analysis under continuous cooling. The authors demonstrated a strong dependence of the temperature for the beginning of ferrite formation and of the transformation time on the austenitizing temperature, due to its effect on the austenite grain size [5].

Offerman et al. [6] studied the kinetics of the austenite/ferrite transformation by synchrotron X-ray diffraction of individual grains, and confirmed the parabolic grain growth model, for the ferritic grains in the initial

\footnotetext{
* Corresponding author. Tel./fax: +55-313-559-1596.

E-mail address: fgabriel@iceb.ufop.br (A.B. Cota).
}

transformation stages. Bengochea et al. [7] studied the evolution of the transformed fraction of deformed austenite into ferrite, under continuous cooling, based on an adaptation of the Johnson-Mehl-Avrami $[8,9]$ theory. They were able to determine the average ferritic grain growth rate with the equation proposed by English and Backofen [10]. Their results show a decrease in the ferritic grain growth rate, as time increases.

This work analyzes the influence of the austenitizing parameters on the kinetics of nucleation and growth of the ferrite grains, during the continuous cooling transformation, for a low-carbon steel, microalloyed with $\mathrm{Nb}$.

\section{Experimental}

The chemical composition of the steel under investigation, expressed in $\mathrm{wt}^{\%} \%$, is $0.15 \mathrm{C}, 1.42 \mathrm{Mn}, 0.37 \mathrm{Si}$, $0.052 \mathrm{Al}, 0.031 \mathrm{Nb}, 0.023 \mathrm{P}, 0.009 \mathrm{~S}$ and $0.0042 \mathrm{~N}$. The samples were austenitized at 900, 1000 and $1100{ }^{\circ} \mathrm{C}$, for $30 \mathrm{~min}$, in order to achieve different austenite grain sizes. They were subsequently cooled in air, before 
quenching at temperatures between $\mathrm{Ar}_{3}$ and $\mathrm{Ar}_{1}$, the temperatures for the start and finish of the austenite/ferrite transformation. The reaction time, $t$, was measured from the instant the sample reached $\mathrm{Ar}_{3}$, until the instant it was quenched. The transformation time, $\tau$, for each austenitizing temperature, was measured between $\mathrm{Ar}_{3}$ and $\mathrm{Ar}_{1}$, in experiments in which the samples were cooled in air until room temperature. The samples were etched with picric acid saturated solution, to reveal the austenite grain boundaries. The microstructural characterization was carried out by light and electron microscopies, to determine the volume fraction and the average grain size of the polygonal ferrite and previous austenite, with the linear intercepts method. An etch with Nital $2 \%$ revealed the ferrite grains, formed before quenching, and the residual austenite, which turns into martensite.

\section{Results and discussion}

\subsection{Austenite grain size}

Fig. 1 shows the evolution of the average austenite grain size with the austenitizing temperature. For the sample austenitized at $1100{ }^{\circ} \mathrm{C}$, the austenite grain size is much larger then for the samples austenitized at lower temperatures. This is a result of the dissolution of a large amount of niobium carbonitrides at that temperature. The niobium carbonitrides hinder the austenite grain boundaries, and inhibit the austenite grain growth, when the austenitizing is performed at lower temperatures.

\subsection{Phase transformation temperatures}

The temperatures for the start $\left(\mathrm{Ar}_{3}\right)$ and finish $\left(\mathrm{Ar}_{1}\right)$ of the austenite/ferrite transformation were determined

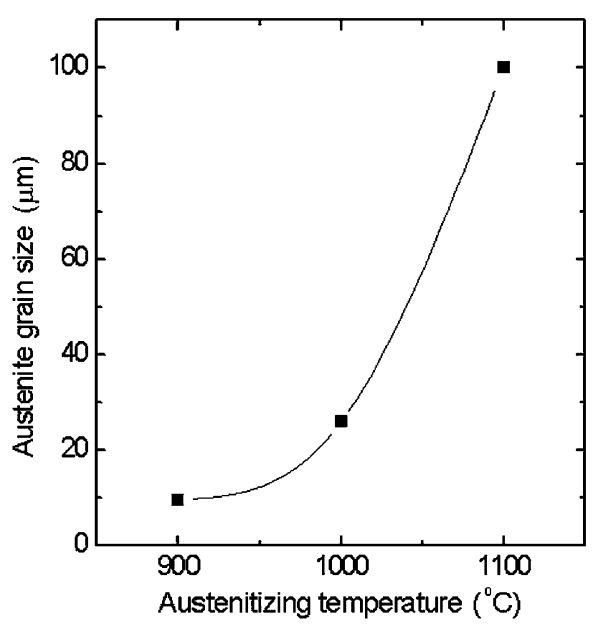

Fig. 1. Effect of the austenitizing temperature on the average austenite grain size, for a $\mathrm{Nb}$ microalloyed steel.

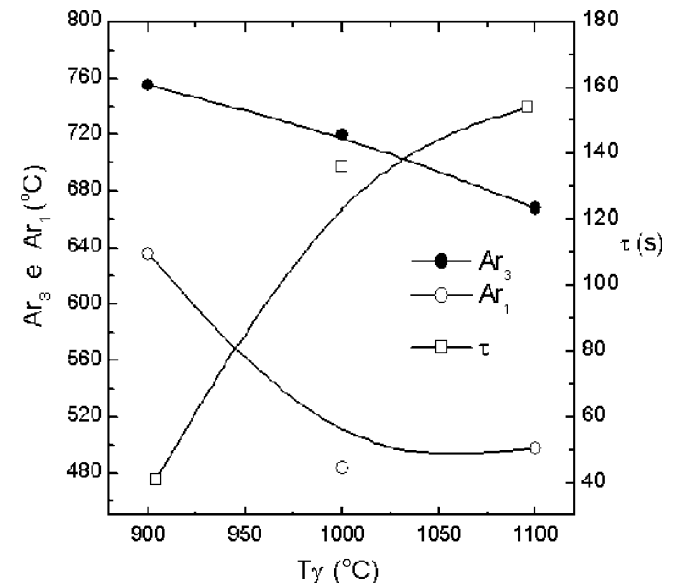

Fig. 2. Temperatures for the start $\left(\mathrm{Ar}_{3}\right)$ and finish $\left(\mathrm{Ar}_{1}\right)$ of the austenite/ferrite transformation, and transformation time $(\tau)$, as a function of the austenitizing temperature, for continuous cooling in air.

by DTA [11] and the results are shown in Fig. 2, of the transformation temperature as a function of the austenitizing temperature. $\mathrm{The} \mathrm{Ar}_{3}$ temperature decreases with an increasing austenitizing temperature. This is a result of the increased average austenite grain size achieved at higher temperatures. A larger austenite grain size leads to a decrease in the number of potential sites for ferrite nucleation, at the austenite grain boundaries, raising the driving force necessary for the transformation.

Quantitatively, the austenite/ferrite transformation may be expressed in terms of $\mathrm{Ar}_{3}$, which is a parameter related to the nucleation for the transformation, and of $\tau$, the transformation time [1]. Fig. 2 shows, together with the tendencies of the transformation temperatures, the dependence of the transformation time with the austenitizing temperature. Higher austenitizing temperatures imply longer transformation times. This is a result of the increased austenite grain sizes, which decrease the $\mathrm{Ar}_{3}$ temperature, delaying the beginning of the austenite/ferrite transformation. Lower $\mathrm{Ar}_{3}$ temperatures imply that the transformation occurs at lower rates, once there is less energy available to activate the reaction and reduced diffusion of carbon. Also, at lower temperatures, the cooling rate in air is lower. Another reason for the increase in the transformation time is the increase in dissolved $\mathrm{Nb}$ that segregates in the austenite/ferrite boundary, slowing it down [1].

\subsection{Microstructural evolution and kinetics of ferrite formation}

Fig. 3 shows photomicrographs of $\mathrm{Nb}$ microalloyed steel samples, austenitized at 900, 1000 and $1100{ }^{\circ} \mathrm{C}$, continuous cooled in air, and quenched from temperatures inside the ferrite-austenite region. For the samples 

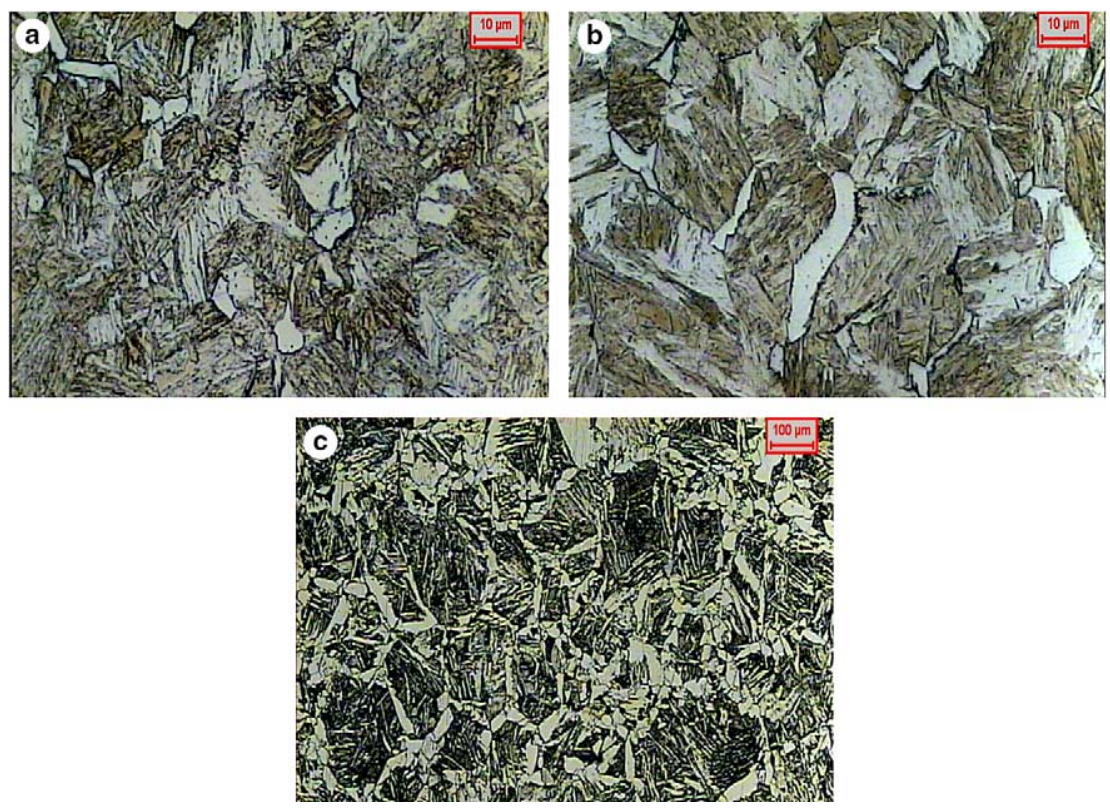

Fig. 3. Photomicrographs of $\mathrm{Nb}$ microalloyed steel samples, continuous cooled in air after: (a) austenitizing at $900{ }^{\circ} \mathrm{C}$ and quenched at $755{ }^{\circ} \mathrm{C}$; (b) austenitizing at $1000{ }^{\circ} \mathrm{C}$ and quenched at $720^{\circ} \mathrm{C}$; (c) austenitizing at $1100{ }^{\circ} \mathrm{C}$ and quenched at $588{ }^{\circ} \mathrm{C}$.

austenitized at 900 and $1000{ }^{\circ} \mathrm{C}$, the microstructure is composed of polygonal ferrite and martensite. In these samples, upon quenching from temperatures close to $\mathrm{Ar}_{1}$, some pearlite was also formed. The microstructure of the samples austenitized at $1100{ }^{\circ} \mathrm{C}$ is, basically, polygonal ferrite, martensite and bainitic ferrite, according to the classification proposed by Krauss and Thompson [12].

The ferrite volume fractions, measured in the samples quenched in water at room temperature, increased with the decreasing of the temperature of interruption of the continuous cooling. Fig. 4 shows the polygonal ferrite

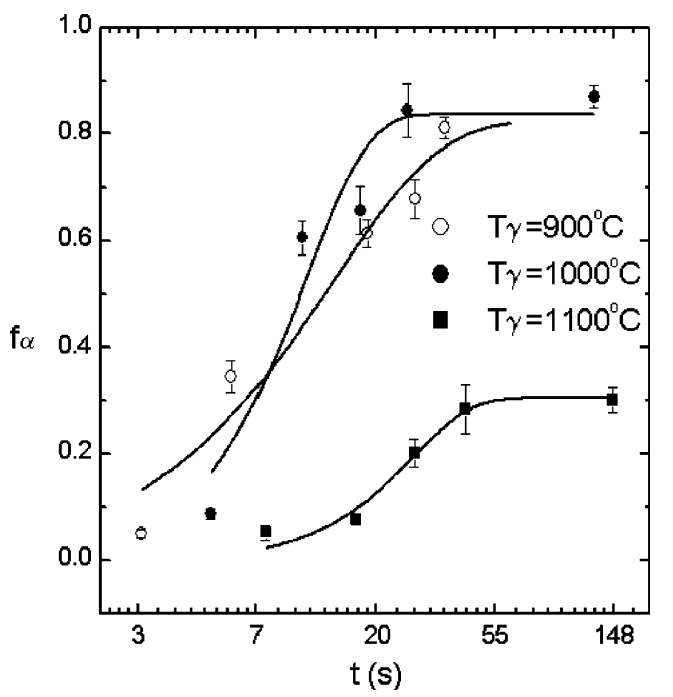

Fig. 4. Ferrite volume fraction, $f_{\alpha}$, as a function of the reaction time, for the austenitizing temperatures of 900,1000 and $1100{ }^{\circ} \mathrm{C}$. volume fraction, $f_{\alpha}$, as a function of the reaction time, $t$, for the three austenitization temperatures. The data were fitted to the Johnson-Mehl-Avrami [8,9] model, expressed by Eq. (1):

$f_{\alpha}=A\left[1-\exp \left(-B \cdot t^{n}\right)\right]$

where $A, B$ and $n$ are constants determined in the curve fitting of the ferrite volume fraction as a function of the reaction time. The fitted semi-empirical equations are listed in Table 1, for the three austenitizing temperatures, together with the correlation coefficients, and the transformation times of austenite to ferrite under continuous cooling.

A closer look into the parameters adjusted for the Johnson-Mehl-Avrami equation, for the $\mathrm{Nb}$ microalloyed steel, reveals a linear relation between the time exponent in the equation, $n$, and the transformation time under continuous cooling, $\tau$. This is shown in Fig. 5, of the coefficient $n$ as a linear function of $\tau$, with a correlation coefficient above 0.999 . It reveals a particular feature of this empirical equation, valid at least for the steel in question that allows the prediction of the transformation time under continuous cooling, directly from the time exponent. Despite the obvious relation between the two values, the relation between them could be non-linear, had $A$ and $B$ values different from those found.

The ferrite grain growth rate may be estimated from Eqs. (2)-(4), together with the equation proposed by English and Backofen [10]:

$g=\left(\frac{1}{S_{\mathrm{v}}}\right)\left(\frac{\mathrm{d} f_{\alpha}}{\mathrm{d} t}\right)$ 
Table 1

Semi-empirical equations for the kinetics of austenite/ferrite transformation, of a $\mathrm{Nb}$ microalloyed steel, under continuous cooling

\begin{tabular}{|c|c|c|c|c|}
\hline Austenitizing temperatures & Equation & & Correlation coefficient $\left(R^{2}\right)$ & Transformation time \\
\hline $900{ }^{\circ} \mathrm{C}$ & $f_{\alpha}=0.82\left[1-\exp \left(-0.05 t^{1.1}\right)\right]$ & (2) & 0.9647 & $41 \mathrm{~s}$ \\
\hline $1000{ }^{\circ} \mathrm{C}$ & $f_{\alpha}=0.84\left[1-\exp \left(-0.01 t^{1.91}\right)\right]$ & (3) & 0.9584 & $136 \mathrm{~s}$ \\
\hline $1100{ }^{\circ} \mathrm{C}$ & $f_{\alpha}=0.31\left[1-\exp \left(-0.001 t^{2.03}\right)\right]$ & (4) & 0.9784 & $154 \mathrm{~s}$ \\
\hline
\end{tabular}

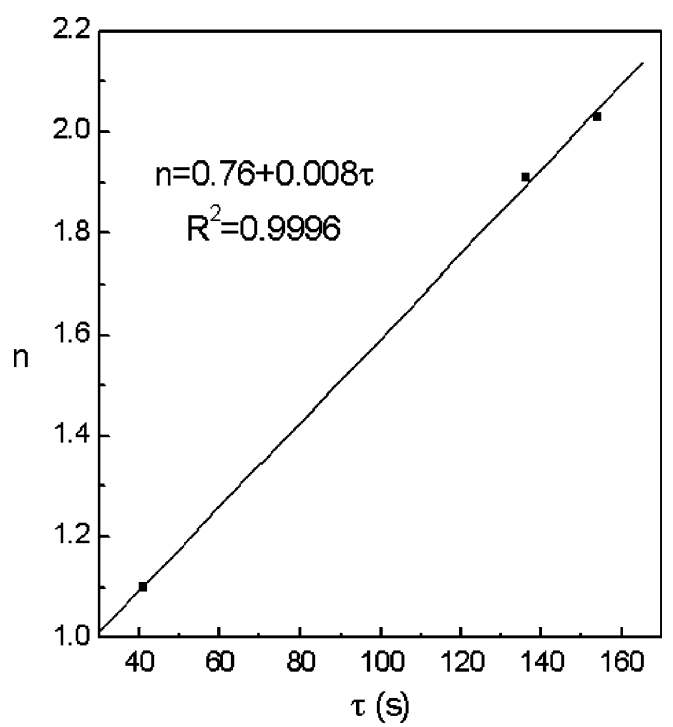

Fig. 5. Johnson-Mehl-Avrami time exponent, as a function of the transformation time, $\tau$, under continuous cooling of a $\mathrm{Nb}$ microalloyed steel.

where $g$ is the ferrite grain growth rate, $S_{\mathrm{v}}$ is the surface area of the austenite/ferrite phase boundary per unit volume and $f_{\alpha}$ is the volume fraction of ferrite at time $t$.

The surface area of the austenite/ferrite phase boundary per unit volume is shown in Fig. 6 as a function of the ferrite volume fraction. It is observed that the higher the austenitizing temperature, the smaller the phase boundary surface area, as a result of the larger austenite grain sizes. A maximum is observed for the $S_{\mathrm{v}}$ versus $f_{\alpha}$ plot, establishing the value at which the growing ferrite grains start to touch each other.

Fig. 7 shows the ferrite grain size, $d_{\alpha}$, as a function of the reaction time, for the three austenitizing temperatures. Higher austenitizing temperatures lead to larger ferrite grain sizes. The larger austenite grain sizes, produced by the higher austenitizing temperatures, decrease the surface area for the nucleation of the ferrite grains, what leads to the production of larger grains. The effect is much more pronounced at the austenitizing temperature of $1100^{\circ} \mathrm{C}$, as a result of the secondary growth of

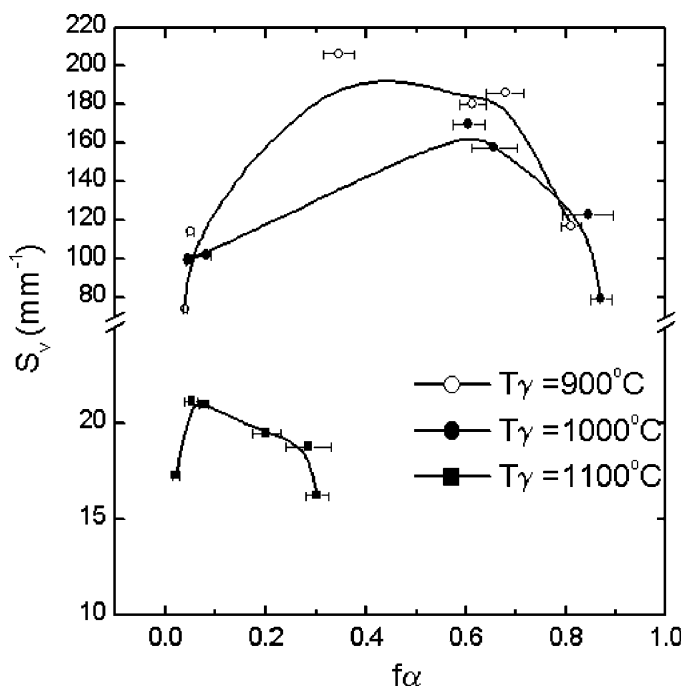

Fig. 6. Surface area of the austenite/ferrite phase boundary per unit volume, $S_{\mathrm{v}}$, as a function of the ferrite volume fraction, $f_{\alpha}$, for the austenitizing temperatures of 900,1000 and $1100^{\circ} \mathrm{C}$.

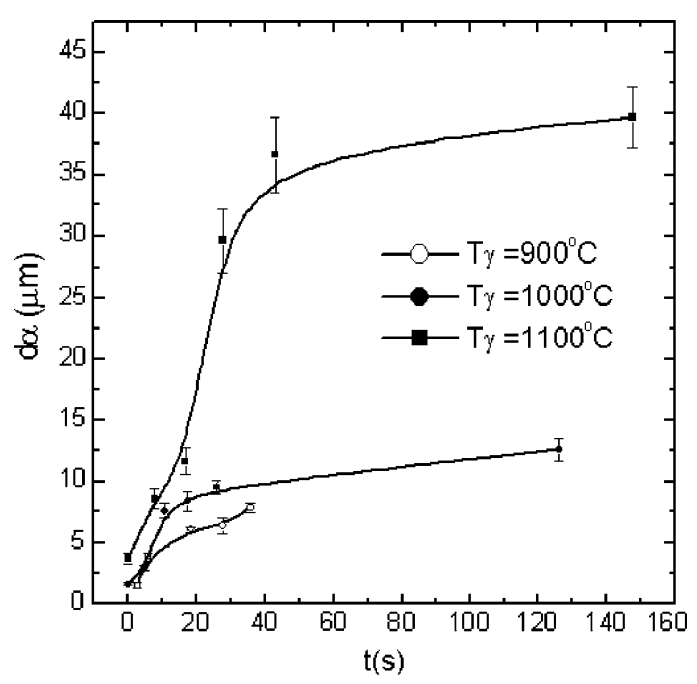

Fig. 7. Ferrite grain size, $\mathrm{d}_{\alpha}$, as a function of the reaction time, for the three austenitizing temperatures of 900,1000 and $1100{ }^{\circ} \mathrm{C}$. 


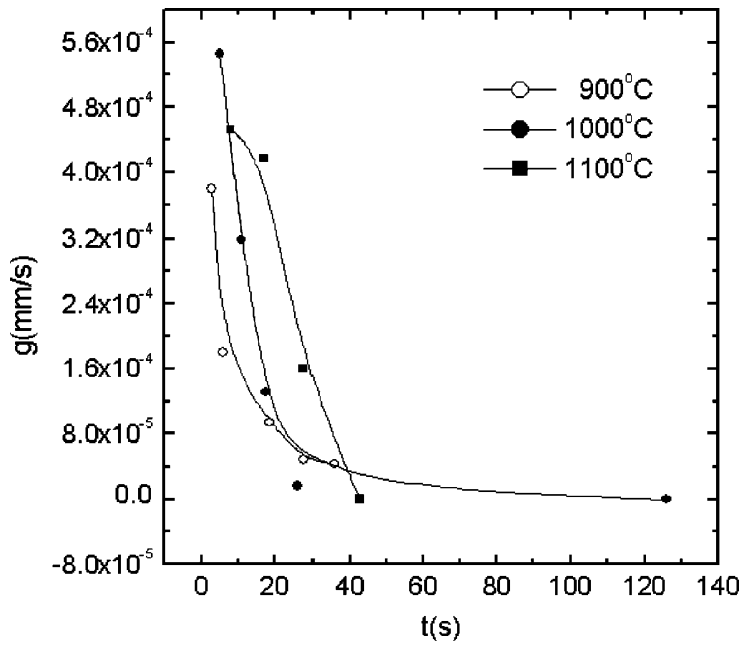

Fig. 8. Average grain growth rate, $g$, as a function of the reaction time, for the three austenitizing temperatures of 900,1000 and $1100{ }^{\circ} \mathrm{C}$.

the austenite grains, caused by the dissolution of the $\mathrm{Nb}$ precipitates.

The coarse polygonal ferrite grain size in the specimen austenitized at $1100{ }^{\circ} \mathrm{C}$ can be explained by the longer reaction times, shown in Fig. 2, despite the fact that $\mathrm{Ar}_{3}$ and $\mathrm{Ar}_{1}$ are at lower temperatures. Grain boundary nucleation between $\mathrm{Ar}_{3}$ and $\mathrm{Ar}_{1}$, for this case, results in a smaller number of nuclei, and the longer reaction times provide the polygonal ferrite coarsening. The grain boundary nucleation sites appear to be saturated early only for the specimen austenitized at 1100 ${ }^{\circ} \mathrm{C}$, because of the smaller interfacial area available.

Fig. 8 shows the average grain growth rate, $g$, as calculated from Eq. (5), as a function of the reaction time, for each austenitizing temperature. There is a decrease in $g$ with the reaction time, once longer times correspond to lower temperatures, at which the atom diffusion decreases. The increase in $g$ with the austenitizing temperature is a result of the smaller degree of grain impingement, together with the lowering of $\mathrm{Ar}_{3}$ that increases the driving force for the reaction.

\section{Conclusions}

For the $\mathrm{Nb}$ microalloyed steel analyzed, the increase of the austenitizing temperature, from 900 to $1100{ }^{\circ} \mathrm{C}$, decreases the $\mathrm{Ar}_{3}$ temperature from 755 to $668{ }^{\circ} \mathrm{C}$, approximately, for continuous cooling in air, and increases the austenite grain size from 9.5 up to $100 \mu \mathrm{m}$. Also, it increases the average ferrite grain size from 8 to about $40 \mu \mathrm{m}$, at the end of the reaction, as well as it increases the ferrite grain growth rate.

Semi-empirical equations, for the ferrite transformed fraction as a function of the reaction time, for the austenitizing temperatures of 900,1000 and $1100{ }^{\circ} \mathrm{C}$, revealed that, for the $\mathrm{Nb}$ microalloyed steel under study in continuous cooling, the time exponent has a linear relation with the transformation time.

\section{Acknowledgments}

The authors are grateful for the financial support of CNPq, FUNDAÇÃO GORCEIX and FAPEMIG.

\section{References}

[1] Manohar PA, Chandra T, Killmore CR. ISIJ Int 1996;36:1486.

[2] Thompson SW, Krauss G. Metall Mater Trans A 1996;27A:1557.

[3] Cota AB, Santos DB. Mater Charac 2000;44:291.

[4] Velthuis SGE, Dijk NH, Rekveldt MTh, Siestsma J, Zwaag S. Mater Sci Eng 2000;A277:218.

[5] Cota AB, Lacerda CAM, Oliveira FLG, Araujo FGS. REM 2002;55:273.

[6] Offerman SE et al. Science 2002;298:1003-5.

[7] Bengochea R, López B, Gutierrez I. Metall Mater Trans A 1998;29:417.

[8] Johnson WA, Mehl RF. Trans AIME 1939;135:416.

[9] Avrami M. J Chem Phys 1941;9:177.

[10] English AT, Backofen WA. Trans Metall Soc AIME 1964;230:396.

[11] Cota AB, Modenesi PJ, Barbosa R, Santos DB. Scripta Mater 1999;40:165.

[12] Krauss G, Thompson SW. ISIJ Int 1995;35:937. 